\title{
Guided Tours Across a Collection of Historical Digital Images
}

\author{
Maristella Agosti \\ Dept. of Information Engineering \\ University of Padova \\ Via Gradenigo 6/a \\ Padova, Italy \\ agosti@dei.unipd.it
}

\author{
Nicola Orio \\ Dept. of Cultural Heritage \\ University of Padova \\ Piazza Capitaniato 7 \\ Padova, Italy \\ nicola.orio@unipd.it
}

\author{
Chiara Ponchia \\ Dept. of Cultural Heritage \\ University of Padova \\ Piazza Capitaniato 7 \\ Padova, Italy \\ chiara.ponchia.1@studenti.unipd.it
}

\begin{abstract}
We propose the use of short lectures, called narratives, embedded in a digital archive as a personalization method to support and guide users within a collection of historical material. The effectiveness of the approach has been evaluated with two groups of users. An analysis of the results has been conducted enabling the presentation of preliminary results.
\end{abstract}

\section{Categories and Subject Descriptors}

H.3.7 [Information Storage and Retrieval]: Digital Libraries collection, dissemination, systems issues, user issues; H.3.5 [Information Storage and Retrieval]: Online Information Services - data sharing, Web-based services.

\section{Keywords}

Cultural heritage collections, digital cultural heritage collections, digital libraries and archives, digital library system, digital humanities, adaptive environment CULTURA project, CULTURA environment, IPSA digital collection, cultural heritage.

\section{INTRODUCTION}

Over the last decade we have witnessed a worldwide effort in digitizing cultural heritage material, carried out by public and private institutions with the frequent aid of public funds. As a result, a considerable amount of historical, artistic and music documents is now available to the general public according to the main goals of accessibility for digital resources: anytime and anywhere. We have been participating in this effort by creating a digital archive of illuminated manuscripts, called IPSA (Imaginum Patavinae Scientiae Archivum). IPSA [1] is a web application designed and developed by the University of Padua, as a joint effort of the Department of Information Engineering and the Department of Cultural Heritage, with the main objective of allowing and facilitating the study of the scientific image iconographic tradition during the Middle Ages and the

Permission to make digital or hard copies of all or part of this work for personal or classroom use is granted without fee provided that copies are not made or distributed for profit or commercial advantage and that copies bear this notice and the full citation on the first page. Copyrights for components of this work owned by others than ACM must be honored. Abstracting with credit is permitted. To copy otherwise, or republish, to post on servers or to redistribute to lists, requires prior specific permission and/or a fee. Request permissions from Permissions@acm.org.

AIUCD'14, September 18-19, 2014, Bologna, Italy

(C) 2014 ACM. ISBN 978-1-4503-3295-8/14/09 ..\$15.00

DOI: $\underline{\text { http://dx.doi.org/10.1145/2802612.2802632 }}$
Renaissance and the analysis of the role played by the University of Padua in promoting scientific culture in Europe. ${ }^{1}$

The IPSA collection includes over 3,400 digitized images from 57 illuminated scientific manuscripts, in particular astrological codices and herbals. The choice of the elements to be represented within the collection, the database structure underlying the web application, and the user interface was designed to fulfil the requirements of specialized users, namely scholars in history of art, history of science, botany, and astronomy. Thus IPSA was initially developed as a tool for scientific research [2].

Relevant IPSA content is also available from the environment of the EU-funded project named CULTURA, ${ }^{2}$ in fact CULTURA has developed an interactive and personalized environment able to offer genuine user empowerment and new levels of engagement with digital cultural heritage collections and communities; this environment can be experienced at URL: http://cultura-project.eu/ where it is possible for the general public to register online and browse IPSA and two other collections of textual documents. In the following, we refer to the instantiation of IPSA within this new environment as IPSA@CULTURA.

\section{USER NEEDS AND EVALUATIONS}

Because one of the main CULTURA goals is to involve new user categories in the digital cultural heritage experience, an important part of the CULTURA activities has focused on elicitation of user requirements and subsequent evaluations, which have been carried out extensively from the very beginning of the project, involving different user categories [3]. In particular, with the aim of redesigning IPSA taking into account the requirements of a wider group of users, the team of the University of Padua undertook a continuous evaluation program [4] with numerous cohorts of undergraduate and master students that were involved in many different evaluation sessions throughout the duration of the project (November 2011; December 2011; April 2012; May 2012; December 2012; October 2013). In parallel, different kinds of interaction were carried out with professional researchers (February 2011; May 2012; December 2013), members of the general public (January 2013; September 2013) and high school students (October 2013).

The frequent and repeated interactions with end users without a specific interest in the IPSA collection and without proper knowledge of the basic concepts of History of Art and History of Illumination highlighted a fundamental challenge that must be

\footnotetext{
${ }^{1}$ http://ipsa.dei.unipd.it/en_GB/home.

${ }^{2}$ http://www.cultura-strep.eu/.
} 
faced by digital cultural heritage providers: the need of raising and maintaining the interest of casual users, who may find it difficult to fully appreciate the value of the digital content and understand the subtle nuances of the artwork. In fact, although a digital collection such as IPSA can be a valuable research tool for professional users, it might be scarcely appreciated by other kinds of users if they are not helped and encouraged to get acquainted with the collection and find an interest in it. In the light of this consideration, it is pivotal for digital cultural heritage providers to reflect on how to shorten distances between specialist knowledge and the general public, if they actually want to succeed in spreading and disseminating. Thus, scholars aiming at disseminating the results of their research work should pay attention not only to the content itself, but also to the proper ways to make it more comprehensible and enjoyable.

In this regard, as a possible solution we propose enriching the functions of a digital archive through short lectures, called narratives, as a personalization method to support and guide users within the collection [5]. Narratives aim at highlighting the richness of the available digital content, which may be difficult to retrieve for non-experts, and to give the users the preliminary information they need to navigate the collection and to take advantage of their interaction with the system. We tested the approach with a task-oriented evaluation [6]. A group of users followed a narrative before using IPSA@CULTURA, while a control group accessed the content directly. Both groups were asked to accomplish a number of tasks, such as retrieving a particular element, annotating a detail of an image, or drawing a link between two related images. Results showed that, since narratives include the usage of the available tools, the user group that followed the guided tour was facilitated in learning how to interact with the system and access relevant content.

\section{NARRATIVES: A SOLUTION TO ENGAGE NEW USER GROUPS \\ 3.1 Guided Tours across the Collection}

The use of narratives was explored during the development of the CULTURA project. In the case of IPSA@CULTURA, these guided tours can be used to introduce the basic concepts of the history of illuminated manuscripts and the content of the collection to underline its peculiarities while at the same time to present the available services of the user interface. These thematic pathways can be thought of as simple lectures where users are invited to follow a number of directions within the collection. At each step the system:

- presents the user with a particular element of the collection (e.g. an illuminated page);

- provides a concise description of the actual research goal and its context;

- $\quad$ suggests to the user a number of tools that can be exploited to accomplish that goal;

- highlights the relevant aspects that might be hidden by the large amount of information accessed by the user at each step;

- supports exploration of the digital content through a number of predefined queries.
Since narratives are added to the original system, users are still free to follow different directions, make new queries, use different tools or simply navigate the collection according to their own particular interests. Narratives aim at maintaining the sustained interest of the users, who are involved in a simple lecture and are guided across the methods and tools of scientific research. Narratives are presented and perceived as additional content to the collection itself. Thus, even if metadata description must follow the guidelines of digital cataloguing and might not be of interest for the general public, narratives can add anecdotal information on the illustration, on its style and technique, on the authors or on the historical period. That fulfills the need for additional and external information that was clearly expressed by users during the evaluations carried out in the first two years of the project.

\subsection{Preparing the Narratives}

The creation of a particular narrative, which can be selected by the user at any moment during a session, needs to be designed by scholars. In the case of IPSA@CULTURA, this was done with the creation of a number of thematic pathways across the collection of herbals and by discussing for instance the way a given iconography evolved over the centuries or introducing the study of illuminated manuscripts, their story, their illustrative systems and the most frequent painting techniques.

The relatively short time required to prepare a narrative, which can be the result of specific scientific research by art historians, shows that the approach is feasible. We aim at introducing narratives as a novel tool for interactive lectures, so that teachers are motivated to add new narratives to the system and possibly also share them with the general public. In this way, IPSA@CULTURA can be increasingly enriched by new narratives, providing the final users with a number of different ways to enjoy the collection.

\subsection{Narratives: the structure}

At any time of their interaction with the system, users are able to select a narrative from a "Lesson block" on the left-hand side of the page. In our evaluations, users could choose from two narratives, "Basic_concepts" and "Tutorial".

After selecting a narrative, users land on the "Lesson start page", which explains how to use the narrative and to navigate through the course. At every step of the narrative a text block on the lefthand side of the page containing shows users the instructions needed to proceed, some simple tasks to perform, or short explanations about the content presented on the right-hand side of the page, such as an illumination or a CULTURA tool (see Figure 1).

In the middle of course users can move from one page to the next by simply clicking on the "Next" button. If they want to step back to the previous page, they can do so by clicking on the "Previous" button. In some cases users can choose between the "Next" button and the "See extra resource related to this one" button to access more detailed information on the issue. This is a very important feature of narratives, because it enables the users to have a personalized experience, tailored to their curiosity and interest towards the particular subject. 


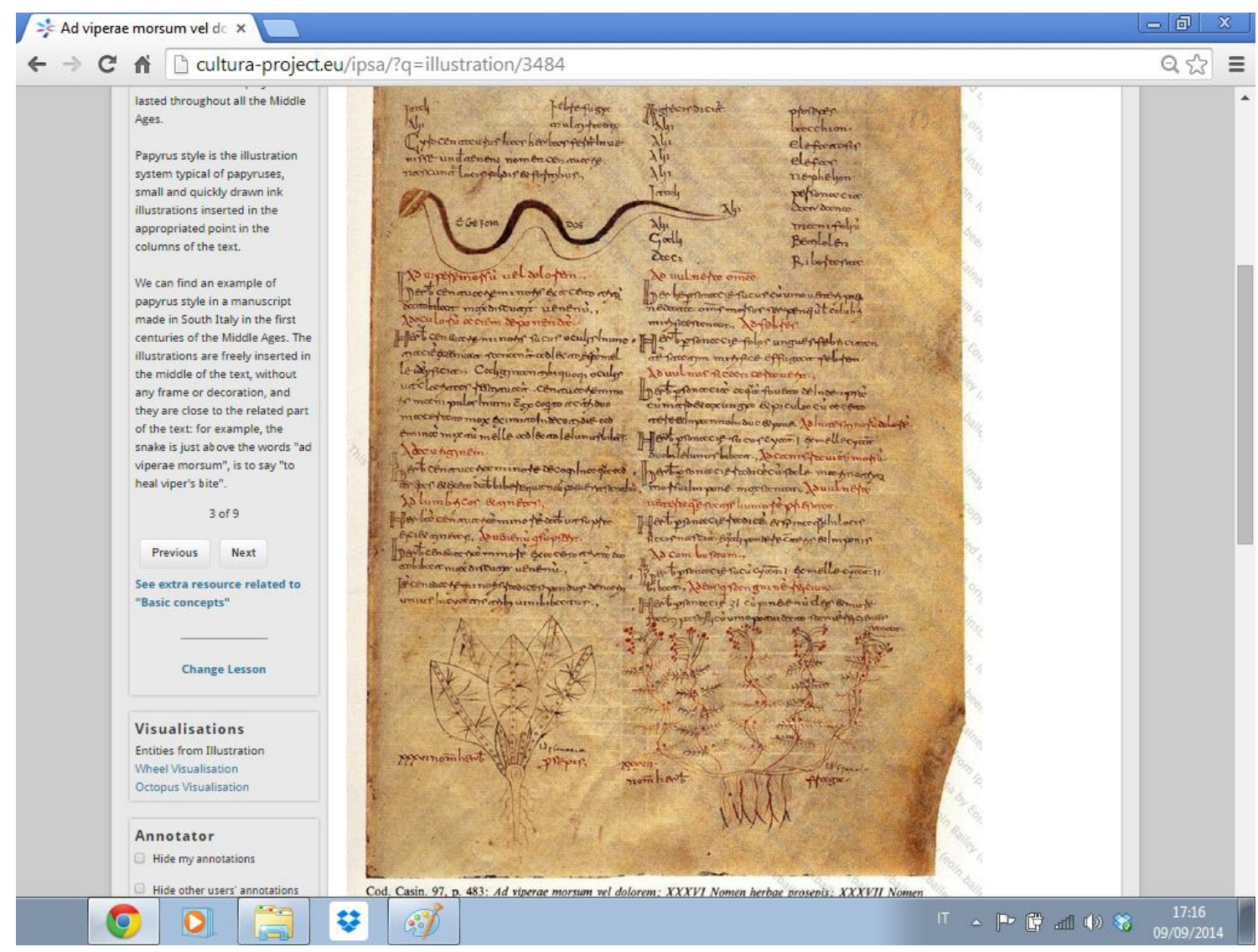

Figure 1. Narrative, an illuminated page.

Thus, users with a low interest can just follow the main steps of the narrative, acquiring only the basic information and completing their experience in a short time, while users who want to know more about what they are looking at can easily get extra content and information. In some cases, extra resources can be links to external websites, thus increasing the amount of information users can receive from this experience.

\subsection{Narratives: the contents}

As mentioned above, currently the system offers two different narratives, "Basic_concepts" and "Tutorial". They both address user needs for preliminary information concerning History of Art and History of Illumination.

"Tutorial" presents the user with the iconographic development of the representation of rosemary from the IX century to the Renaissance. In fact, the IPSA rich collection, which holds illuminations belonging to herbals dated from the IX to the XVI century, allows scholars to verify how botanic subject representations changed across the centuries, according to the change of scientific mentality and artistic trends. The rosemary representation recurs in many herbals of the collection, thus it appeared as the most suitable choice to create a guided tour through IPSA@CULTURA contents, showing the user what a herbal is, what an illumination is and how style evolved from the IX century to the Renaissance. The "Tutorial" narrative involves the user in research process adopted by scholars, showing how professional researchers reconstruct image chains of derivation. Nevertheless, it must be underlined that the value of the "Tutorial" narrative does not reside just in the content: during the course of the narrative the user is also presented with the main CULTURA tools needed to do his own research once he has completed the lesson.

The narrative begins with the description of a Renaissance rosemary illumination, highlighting the peculiarity of the lay-out of the page and explaining what elements make that image of such high quality. Afterwards, the user is invited to save the page through the "Bookmark Page" button and to proceed with the tour or to access some extra resources. In that case, he will be shown another Renaissance rosemary illumination, where he can appreciate the same high quality details as in the previous illumination. After this insight, he will return to the narrative. At this step, the "Visualization Tool" (Figure 2) is presented in order to explain its functions to the user and to lead him to the beginning of the rosemary chain of derivation, that is to say a IX century drawing from a Montecassino manuscript (Florence, Laurenziana Library, ms. Plut. 73.41, f. 46r). Also in this case the user is given the possibility to access some extra material, this time a contemporary drawing from another Montecassino manuscript (Montecassino, Badia Archive, Casin. 97, f. 500r). Afterwards, the narrative proceeds by presenting another crucial passage of the rosemary chain of derivation, a rosemary representation in a XIII century manuscript created at the court of emperor Federico II (Vienna, Osterreichische Nationalbibliotek, Codex Vindobonensis 93, f. 83v). The rosemary chain of derivation ends with the Renaissance illumination presented at the beginning of the lesson, which can now be better appreciated by the user. Finally, the narrative is completed by the mandragora chain of derivation. 


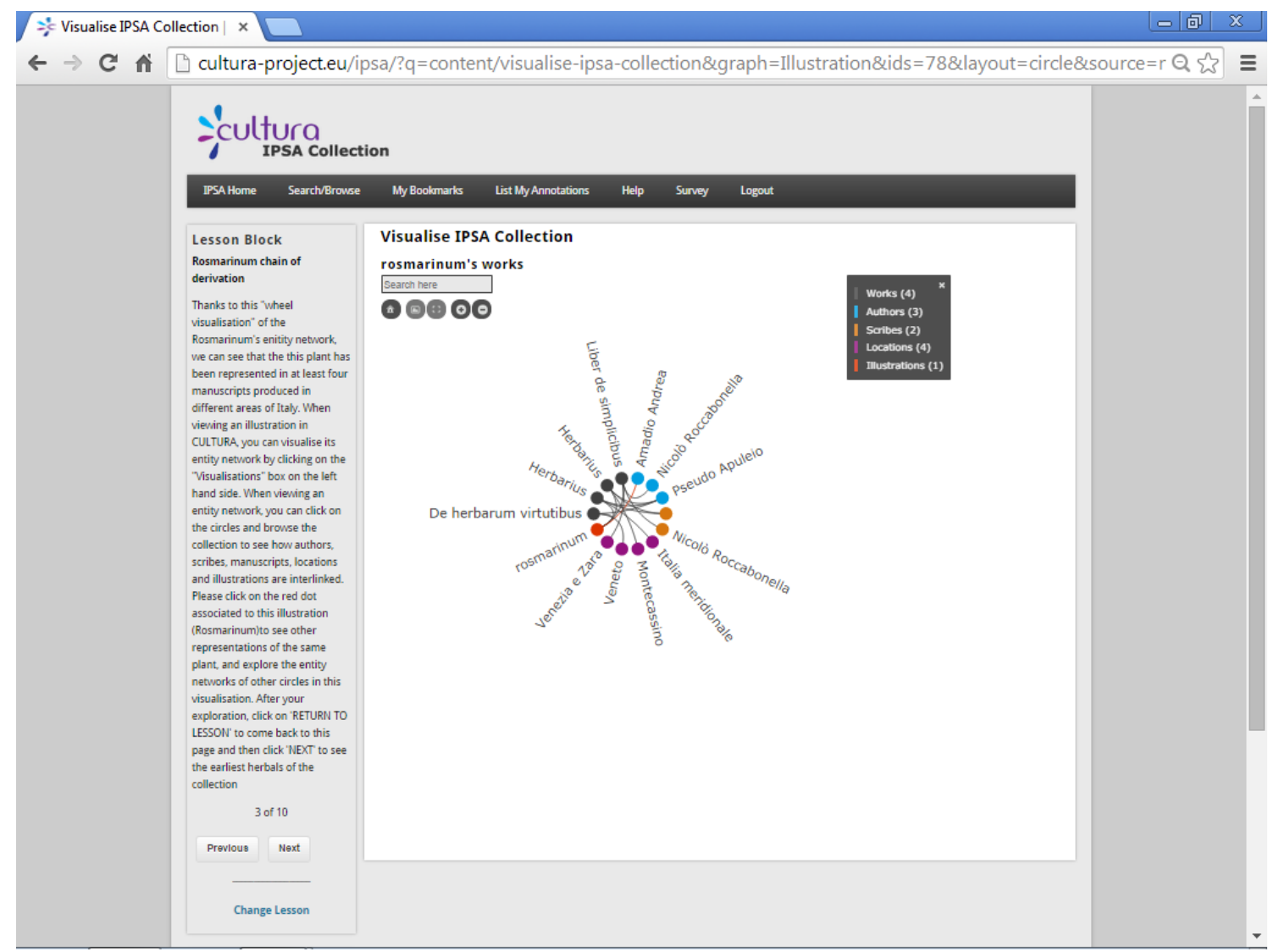

Figure 2. Visualization tool inside a narrative.

Mandragora is an imaginary plant, half-human and half-vegetable, that in the Middle Ages was thought to be real. The representation of the human part of the mandragora helps the user to gain a better understanding of how the style developed between the XIII and the XVI century, because this change can be more clearly observed by comparing a human figure rather than a plant. On the last page of the narrative, the user is invited to use the search features to explore IPSA@CULTURA some more.

The "Basic_concepts" narrative aims to teach the user the most important concepts of the History of Illumination, the is to say: the correct vocabulary about illumination, the history of illuminated manuscripts from the introduction of parchment to the invention of the Gutenberg printing press, with some insights into the main illustration systems and illustration techniques.

A correct vocabulary is pivotal to explore the collection and to understand the images metadata. In fact, there are a few technical words that are essential for reading a manuscript description. Hence, the narrative presents the user with an illumination catalogue file, defining all the technical words one by one, e.g. "Call number", which is a unique code used to identify the book. Also some other useful explanations are given, about the most common abbreviations, such as " $\mathrm{r}$ " and " $\mathrm{v}$ " for recto and verso of a page, or "f." and "ff." for folio and folii, and about the different fields of the catalogue form, such as "Codicological notes" where the user can read the description of the internal division of the book.
The second part of the narrative is dedicated to the history of illuminated manuscripts, with many insights on related subjects.

History of manuscripts began in the Late Antiquity and it is closely related to the spread of the parchment as a writing material. Before of this crucial event, the most common writing material was the papyrus, that was not suitable to be stitched in quires and to be painted. The "Basic_concepts" narrative explains the user the difference between a papyrus scroll and a parchment manuscript, dealing also with the different illustrative systems associated with these two different writing supports: the so-called papyrus style and the framed illustrations that became more common in parchment illuminated manuscripts. Examples of both the illustrative systems are taken from the IPSA collection material (Montecassino, Badia Archive, Casin. 97, f. 483r as an example of papyrus style; Bergamo, Angelo Mai Library, ms. MA 593 , f. $1 \mathrm{r}$ as an example of framed illustration). Afterwards, the user can access some extra resources on other illustrative systems, and then decide to come back to the lesson.

The narrative proceeds presenting other illuminations from the IPSA collection and using them as different examples to explain the main illustration techniques: ink drawings (Firenze, Laurenziana Library, ms. Plut. 73.41, f. 57r), painting with selfmade colours prepared with minced plants and rocks (London, British Library, ms. Egerton 2020, f. 4r), watercolour painting (Bergamo, Angelo Mai Library, ms. MA 592, f. 4r). In this case, a link to a Wikipedia webpage on the watercolour painting technique is presented as an extra resource (Figure 3). 


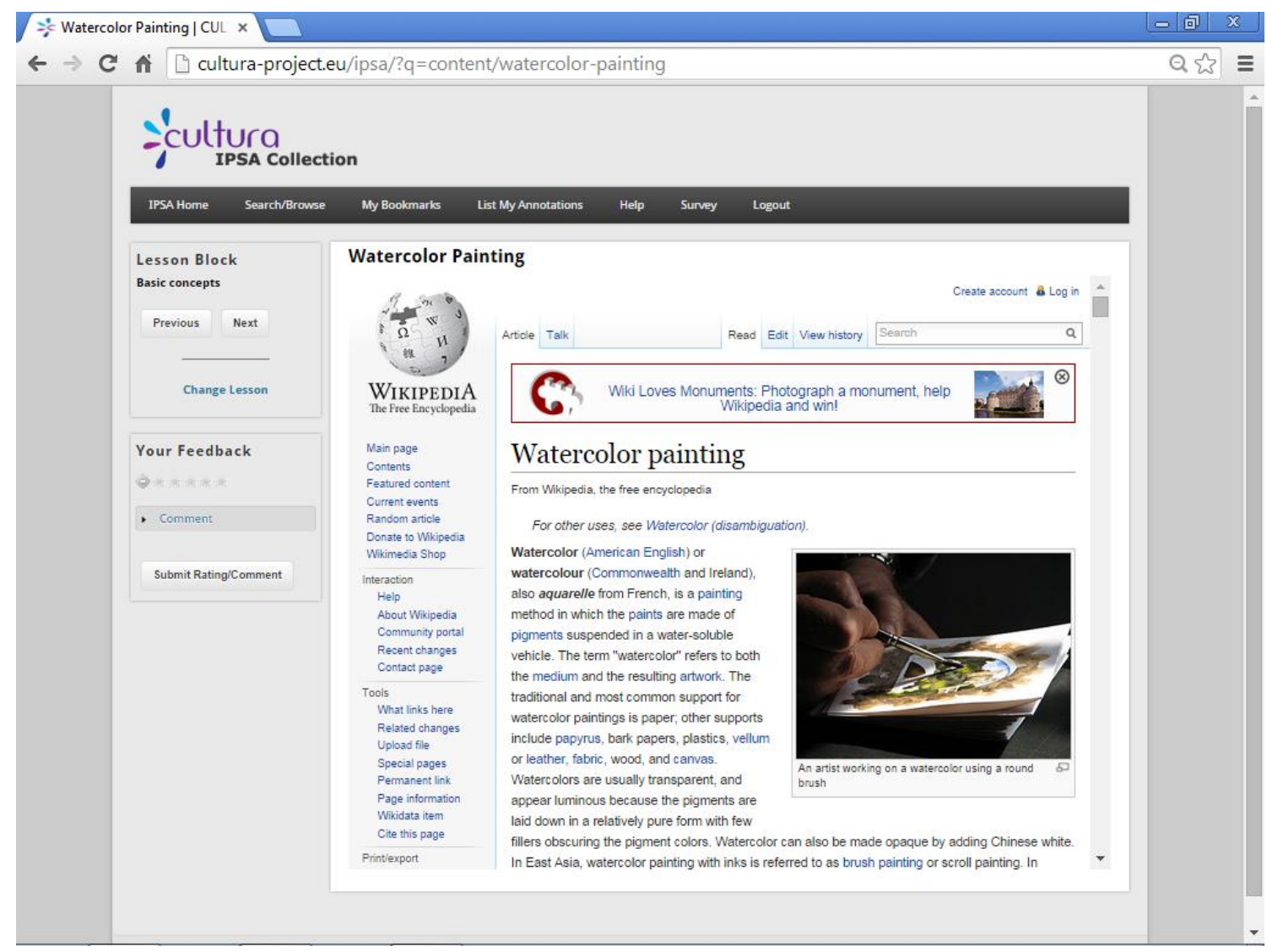

Figure 3. Narrative, a link to an external resource.

The narrative concludes by calling the user's attention to another important aspect of illuminations: they are not just beautiful works of art, but also precious documents of the past as well.

To clarify this concept, the user is presented with an illumination depicting a physician teaching a young student the medical virtues of garlic (Bergamo, Angelo Mai Library, ms. MA. 592, f. 3v). Here the user can observe how people dressed in the XV century, and even the differences between adults and young people, because the physician is wearing a very long and elegant red cloak with a fur collar and hood, while the young figure is wearing completely different garments: the upper garments are shorter and very tight-fitting on the hips, below he is wearing brilliant-green britches and on his head he is sporting a large funny hat. The illumination reflects contemporary textual documents, where writers complained about the strange way young people wanted to dress.

\section{NEW EVALUATIONS}

After developing the narratives, in October 2013 we carried out new evaluations with two groups of users in order to evaluate whether the use of narratives can effectively improve the experience of accessing the digital collection and maintain a higher level of interest.

In line with previous evaluations, we exploited a task-oriented approach, while the evaluation approach was based on the triptych model of interaction [7]. As with previous evaluations, we focused on the relation between the user and the content. We carried out two trials, with two different cohorts of students. The first cohort consisted of students attending the DILL master, a two-year international master on digital libraries offered in cooperation between Oslo and Akershus University College of Applied Sciences (Norway), Tallinn University (Estonia), and the University of Parma (Italy). ${ }^{3}$ The second cohort was formed by students from an arts high school in Padua. In both cases, the participants were divided into two groups. Each participant was asked to perform a simple research task on the digital collection, requiring about one hour of interaction that permitted use of most of the available IPSA@CULTURA functions. In order to evaluate the efficiency of the narratives, one group was asked to carry out the task after - or during if they preferred - having followed a narrative, while the second group had to carry out the task directly. At the end of the trials, participants were asked to fill in an online questionnaire specially developed by a team of psychologists from the University of Graz, which was a partner of the CULTURA consortium. Comments were also gathered orally during the evaluation and through an open discussion after the conclusion of the evaluation.

Both the feedback provided by the questionnaires and the orally gathered opinions suggest that the usage of narratives actually improves user involvement with the digital content and increases user satisfaction in interacting with the system. In particular, it emerged that some characteristics of the interface, e.g. the ability to annotate small details of an image, were difficult for the participants to grasp without a proper explanation. In fact, this tool is specifically developed for professional users, and general users can better understand its usefulness through a narrative

\footnotetext{
${ }^{3}$ http://dill.hioa.no/.
} 
explaining how scholars employ it for their studies and research. On the other hand, tools already available in popular sites, such as social networks, did not present particular problems. In particular, the familiarity with social networks made users appreciate tools that allow collaborative research.

Furthermore, evaluations revealed that narratives help in increasing user interest towards the collection, because they are provided with the proper information that allow them to appreciate an uncommon discipline such as the History of Illumination, that otherwise would be slightly difficult to understand. It is interesting to notice that users showed a greater interest when they could connect what they were seeing to their personal experience. For example, it was particularly interesting for Paduan users to find out more about the history of the University of Padua and the important role it played in the spreading of scientific culture.

\section{CONCLUSIONS}

We present the results of a long-term project that involved the creation of a digital collection of illuminated scientific manuscripts, called IPSA, and its inclusion within the test collections used in CULTURA as a case study to showcase the innovative tools developed during the three-year project. During the execution of the projects interesting and demanding issues emerged, including the challenge to raise general public interest towards very specialist contents.

The solution we propose - the use of simple lectures, structured at different levels in order to harmonize with user interest - appears to be a feasible and valid one and we propose to further develop the creation and implementation of narratives according to new evaluation results.

\section{ACKNOWLEDGMENTS}

The work reported has been partially supported by the CULTURA project as part of the Seventh Framework Programme of the European Commission, Area "Digital Libraries and Digital Preservation" (ICT-2009.4.1), grant agreement No 269973. The work of Maristella Agosti has been partially supported also by the PREFORMA project (contract n. 619568) in the context of the EU FP7.

\section{REFERENCES}

[1] Agosti M., Benfante L., and Orio N. 2003. IPSA: A Digital Archive of Herbals to Support Scientific Research. In Proceedings of the 6th International Conference on Asian Digital Libraries, Kuala Lumpur (MY). Springer, Heidelberg, 253-264.

[2] Agosti, M. and Orio, N. 2012. User Requirements for Effective Access to Digital Archive of Manuscripts. Journal of Multimedia 7, 2, 217-222.

[3] Hampson, C., Agosti, M., Orio, N., Bailey, E., Lawless, S., Conlan, O., and Wade, V. 2012. The CULTURA project: supporting next generation interaction with digital cultural heritage collections. In Proceedings of the 4th Int. Euromed Conference, Limassol (CY). Springer, Heidelberg, 668-675.

[4] Steiner, C.M., Agosti, M., Sweetnam, M.S., Hillemann, E.C., Orio, N., Ponchia, C., Hampson, C., Munnelly, G., Nussbaumer, A., Albert, D., and Conlan, O. 2014. Evaluating a digital humanities research environment: the CULTURA approach. International Journal on Digital Libraries 15, 1, 53-70.

[5] Conlan, O., Staikopolous, A., Hampson, C., O'Keeffe, I., and Lawless, S. 2013. The Narrative Approach to Personalisation. New Review of Hypermedia and Multimedia 19, 2, 132-157.

[6] Ponchia, C. 2012. Engaging the User: Elaboration and Execution of Trials with a Database of Illuminated Images. In Proceedings of the 8th Italian Research Conference on Digital Libraries, Bari (IT). Springer, Heidelberg, 207-215.

[7] Fuhr, N., Tsakonas, G., Aalberg, T., Agosti, M., Hansen, P., Kapidakis, S., Klas, C.-P., Kovács, L., Landoni, M., Micsik, A., Papatheodorou, C., Peters, C., and Solvberg, I. 2007. Evaluation of Digital Libraries. International Journal on Digital Libraries 8, 1, 21-38. 